\title{
Antropología de la música en China Un estudio crítico
}

\author{
Yang $M u$
}

Este artículo proporciona un estudio actualizado y crítico de la antropología de la música en China de 1949 a 200I. Trata los principales temas teóricos, las inquietudes y los enfoques que prevalecen entre la comunidad académica relevante en China. En China el estudio etnomusicológico se desarrolló sobre todo durante la segunda mitad del siglo XX, y ha progresado enormemente desde principios de la década de 1980. Los logros considerables incluyen el discernimiento y desarrollo de la teoría de la temperamentología china, el registro y la grabación de abundante material de música tradicional y popular, los hallazgos arqueológicos de música e instrumentos musicales antiguos, así como nuevas tendencias desarrolladas durante la década pasada. No obstante, existen graves problemas; los más importantes pueden agruparse en cuatro aspectos: la interferencia política, la limitante a estudiar a la música china en sí, un fuerte nexo con el viejo estilo de enfoque musicológico, que aisla al estudio de otras disciplinas aun de su disciplina original, la antropología; y la ignorancia de la teoría y metodología recientes, así como de sus desarrollos en los estudios académicos fuera de China.

This article provides an up-to-date and critical review of Anthropology of music in China, with emphasis on the situation of mainland China from 1949 to $200 \mathrm{l}$. It deals with the main theoretical issues, preoccupations and approaches prevalent among the concerned scholarly community there. In China Ethnomusicological study mainly developed in the second half of the 20th century, and it has advanced enormously since the early 1980s. Outstanding achievements include sorting out and developing the theory of Chinese temperamentology, collecting and recording the abundant traditional and folk musical materials, Archaeological findings of ancient music and musical instruments, and some new trends developed in the past decade. However, serious problems exist and the most fundamental ones can be grouped into four aspects: political interference; confinement to Chinese music itself; a strong attachment to the old style musicological approach, isolating the study from other disciplines including even its parent discipline, Anthropology; and ignorance of recent theory, methodology and their developments in academic studies outside of China.

YANG MU: University of New Saouth Wales, Australia.

Desacatos, núm. 12, otoño 2003, pp. 24-44.

- Traducción de Isabelle Marmasse. 


\section{INTRODUCCIÓN}

$\mathrm{E}$ n el campo académico de la antropología de la música, o etnomusicología, existen muchas publicaciones sobre la música china en otros idiomas además del chino. Sin embargo, muy pocos se dedican a presentar un estudio de la condición de la etnomusicología en China. Para tales estudios vale la pena mencionar tres: el de Isabel Wong (1991), el de Alan Thrasher (1993) y el mío (1998b). El artículo de Wong es un recuento cronológico del desarrollo de la musicología moderna en la China continental desde 1910 hasta mediados de la década de 1980. Muy breve en general, el recuento también es desequilibrado puesto que otorga más de dos terceras partes del contenido a la situación antes de 1949, año en que se estableció la República Popular Comunista de China (en lo sucesivo RPCh). Este tratamiento no se corresponde con el hecho de que en China el mayor desarrollo en la materia ocurre después de 1949. No obstante, el artículo de Wong proporciona una útil introducción para lectores con poco o ningún conocimiento sobre la situación en China. El artículo de Thrasher busca ofrecer un informe más detallado del saber y materiales en el campo de la música china tanto dentro como fuera de China, y cubre el vasto periodo histórico que va del siglo $\mathrm{V}$ a.C. hasta 1980. Incluye una bibliografía bastante valiosa de la literatura china y occidental en este campo.

En los estudios de Wong y Thrasher pareciera que el objetivo es ofrecer información introductoria y descriptiva más que un análisis profundo. Ambos estudios proporcionan breves resúmenes de ciertos temas teóricos, enfoques y perspectivas en el campo de la etnomusicología en China, pero sin una discusión intensa sobre la situación. También parece que los resúmenes de estos autores se derivan principalmente del estudio en publicaciones accesibles, sin el apoyo de la experiencia de primera mano como la investigación in situ u observación participativa entre la comunidad académica interesada en China. No es de sorprender, por consiguiente, que ambos resúmenes se queden cortos en penetración y que hayan pasado por alto algunos temas centrales respecto a la situación en ese país. En contraste, mi artículo se enfoca a la metodología aplicada a la investigación de la música en la RPCh hasta 1998. Se trata de un estudio crítico, ofrece algunos datos perspicaces y actualizados, toca algunos temas centrales y hace algunos comentarios analíticos. No obstante, como se reconoce en el mismo artículo, es muy breve y por ende faltan más detalles y discusión.

El presente artículo busca proporcionar un estudio más detallado y actualizado de la etnomusicología o antropología de la música en China. No aspiro a presentar una introducción completa a esta disciplina en aquel país, sino ofrecer un estudio agudo y crítico de la situación respecto a los principales temas teóricos, intereses y enfoques que prevalecen entre la comunidad académica china interesada. Me enfoco al periodo después de 1949 y me concentro en la China continental, aunque también menciono la situación antes de 1949 e incluyo Taiwán y Hong Kong. ${ }^{1}$

Durante la primera mitad del siglo XX, China estuvo asolada por guerras incesantes — guerras civiles, luego la Segunda Guerra Mundial, seguida inmediatamente por guerra civil otra vez. El clima social no era favorable al estudio académico. Poco se había logrado en el estudio de la música. En 1949, el Partido Comunista Chino ganó decisivamente la guerra contra el Partido Nacionalista y estableció la RPCh, en tanto que el Partido Nacionalista y su gobierno se retiraron a Taiwán y ahí se establecieron. Entonces ambos bandos tuvieron un periodo de relativa paz en el cual desarrollaron sus sistemas académicos.

El estudio de la etnomusicología se ha llevado a cabo de manera notable. En la China continental, para mediados de los años sesenta, tal estudio casi había alcanzado la condición de una virtual disciplina académica. Pero dicho desarrollo se interrumpió por la caótica "Revolución Cultura” (1966-1976) y los años traumáticos subsecuentes. El estudio de la etnomusicología se retomó a finales de la década de 1970, y pronto recuperó su fuerza y se extendió. Para la década de los años noventa, la comunidad de etnomusicólogos de la RPCh se había vuelto

\footnotetext{
${ }^{1}$ En este artículo al mencionar "China” se incluye a Taiwán y Hong Kong; la "República Popular de China" (RPCh) se refiere a los territorios bajo el control actual del gobierno de Beijing, incluyendo Hong Kong después de 1997; la "China continental” excluye tanto a Taiwán como a Hong Kong.
} 
quizá la más grande en el mundo. Concurrentemente, en Taiwán, desde 1950 el estudio etnomusicológico ha seguido desarrollándose a un paso moderado y sin interrupción. El estudio comparable en Hong Kong fue mucho más débil que en la China continental o Taiwán. Desde mediados de la década de 1980, no obstante, unos cuantos etnomusicólogos formados en Estados Unidos encabezan el estudio en Hong Kong, y se ha establecido un estilo estadounidense de práctica etnomusicológica con fuerte énfasis en la música china.

\section{LA ETNOMUSICOLOGÍA NACIONALISTA: EL ESTILO CHINO}

Tras algunos desacuerdos e intensos debates durante la década de 1980, los académicos interesados en China sentaron la opinión de que su estudio es representativo de la etnomusicología de China, y que la etnomusicología moderna en China comenzó con el trabajo de Wang Guangqi (1892-1936) durante la década de 1920, si bien etnomusicología - en un tema de música china (1934), menos de dos años antes de su muerte prematura. $\mathrm{Pu}$ blicó profusamente en chino, alemán e inglés sobre temas relacionados con la música. Su investigación se llevó a cabo por completo en Alemania, siguiendo el enfoque de la entonces escuela alemana de musicología comparada. Algunas de sus monografías son las primeras publicaciones chinas sobre música de Occidente, China y otros países no occidentales (p. ej. 1926, 1929a, 1929b).

Los que afirman que Wang es el precursor de la etnomusicología en China no prestan atención a un punto importante: en su época, Wang era el único académico chino dedicado al estudio comparado de la música de China y otros países no occidentales, y durante los siguientes cincuenta años no se realizó más investigación académica de este tipo en la China continental. En Taiwán la situación era ligeramente mejor, pero en esencia la misma. En términos generales, desde el tiempo de Wang, el así llamado estudio etnomusicológico en China ha estado (y en gran medida sigue estando) restringido a la misma música china. Limitado así, la atención se ha centrado sobre todo en tres campos de la música: etnografía, estudio histórico y morfología (el estudio de las estructuras y formas musicales). Los estudios en estos tres campos comprenden: teoría clásica de la música, antiguas estéticas de la música, instrumentos y música instrumental, canciones populares, teatro tradicional (más comúnmente conocido en Occidente como "ópera china”), cantos narrativos, música de danza y música religiosa. Desde principios de la década de 1980, no obstante, el estudio se ha extendido poco a poco más allá de su alcance previo, para incluir metodología de la investigación etnomusicológica, música del mundo, así como influencias e intercambios musicales entre China y otros países. Sin embargo, la tendencia principal del estudio se confina todavía a la música china.

Si consideramos el estudio de la música tradicional y popular de otros países como un componente esencial de la etnomusicología, entonces podemos decir que en China el desarrollo de dicha disciplina se detuvo por lo menos durante medio siglo después de Wang. Incluso el estudio que se ha realizado en China durante las últimas dos décadas apenas puede considerarse etnomusicolo-
Un grupo de estudiantes del Conservatorio Central de Música (Beijing) realiza caifeng en la ciudad de Tangshan (al este de la capital), que fue dañada por un terremoto en agosto de 1982. El autor es el primero a la derecha. 
gía propiamente. Aunque, por supuesto, el interés de la investigación antropológica hoy en día ya no está limitado al ámbito de examinar a las sociedades y culturas de otros pueblos y países; realizar estudios de campo en su propio país o ciudad y estudiar su propia sociedad y cultura también constituyen importantes tareas antropológicas. Esto justifica la opinión china mencionada con anterioridad de que la etnomusicología en China comenzó con el trabajo de Wang y ha continuado desde entonces. Respecto a la antes mencionada limitación, no obstante, yo diría que el tipo de estudio que se realiza en China es "etnomusicología nacionalista", y lo discutiré como un tema importante a continuación.

\section{CAUSAS CONTEMPORÁNEAS Y TRADICIONALES}

¿Por qué en China se ha limitado el estudio de la etnomusicología a la misma música china? ¿Por qué nunca nadie ha emprendido descubrir o discutir las causas de esta limitación? Ambas preguntas son dignas del escrutinio académico que, no obstante, nunca se lo ha cuestionado.

Tras el establecimiento de la RPCh, una de las tareas más importantes del gobierno era construir una identidad nacional unificada para ese nuevo país comunista. Una tradición cultural unificada era ciertamente esencial para tal construcción nacionalista. En el campo de la música, la gran prioridad era, naturalmente, la música china. Se les exigió a los académicos estudiar e identificar - de hecho, en muchos casos esto significó construirrasgos y características nacionalistas unificados de la música china, que se correspondieran con la ideología comunista y las necesidades políticas del gobierno. Además, desde 1949 hasta la década de 1970, el gobierno de la RPCh aplicó firmemente una política de aislar al país del intercambio internacional, sobre todo con los países capitalistas. Después de los años cincuenta, incluso las relaciones del país con la Unión Soviética y los países de Europa Oriental se deterioraron y los lazos políticos y culturales con dichas naciones comunistas se redujeron al mínimo. La RPCh limitó su atención a la propia China continental, separada del resto del mundo. Esta política de aislamiento se conoció en Occidente como "la cortina de bambú". Por motivos políticos, no se permitía la entrada de ninguna información al país excepto algunos datos muy selectos y aprobados por el gobierno. No se permitió viajar al extranjero con excepción de algunos cuantos funcionarios del Partido y del gobierno.

Sin ninguna posibilidad de realizar estudios de campo en el extranjero, y sin ninguna forma de obtener datos relevantes, el estudio de la música no china era prácticamente imposible. ${ }^{2}$ Las dificultades financieras también incidieron. Aun si se hubieran permitido los estudios de campo en el extranjero, nadie hubiera podido costearlos. Las dificultades financieras fueron cediendo poco a poco en la década de 1980 y siguieron disminuyendo en la de 1990, pero incluso ahora la mayoría de los investigadores en la RPCh aún no pueden sufragar los costos de viajes de estudio de campo en el extranjero.

La enorme mayoría de los etnomusicólogos chinos se encuentra en la China continental. Allí es común que los académicos eviten examinar y discutir abiertamente la situación política nacional a menos que estén arguyendo a favor del Partido Comunista. Criticar públicamente al Partido o a la política del gobierno es un suicidio político. Tal conducta también pondría en peligro su propia carrera académica —a alguien etiquetado como disidente político puede negársele el derecho de publicación para siempre, e incluso se arriesga a ser encarcelado y/o a perder el empleo- - En años recientes, en que el clima político y social en la RPCh se ha relajado bastante, la gente sólo critica al Partido y al gobierno en privado, o critican sólo a los individuos corruptos dentro de éstos. Muy pocos se atreven a criticar a las autoridades en público, y mucho menos a publicar tales críticas. En los

\footnotetext{
2 Sin embargo, el estudio de la musicología histórica occidental siempre existió en la RPCh, porque para tal estudio ya había abundante información, conocimiento y maestros antes de 1949. También se importó un limitado conocimiento durante la década de 1950 de la entonces Unión Soviética y de los países comunistas de Europa Oriental. Sin embargo, no es de sorprender que hasta la política de "puerta abierta” de la RPCh, en la década de 1980, tales estudios eran anticuados y contaba con datos desactualizados y confinados a la música clásica occidental. Incluso hoy en día ese sigue siendo el caso.
} 
estudios e investigación académicos, en general, la gente evita tocar temas políticamente sensibles; nadie quiere escarbar en la mugre política y mucho menos enfangarse en lodo peligroso. Entonces, mientras el estudio etnomusicológico en la RPCh esté atrapado en la restricción política nacionalista, nadie querrá discutir esta situación y sus causas.

Con un examen más profundo pueden rastrearse las raíces del nacionalismo chino hasta la prolongada historia feudal-imperial, las tradiciones y la cultura. El etnocentrismo, o más específicamente, el sinocentrismo, han prevalecido en China por más de dos mil años. Hasta mediados del siglo XIX, los chinos consideraban que su nación era superior a las demás y que estaba ubicada en el centro del mundo; los otros países eran periféricos y sus pueblos y culturas eran bárbaras e inferiores. Esta ideología sigue siendo parte de una fuerte tradición cultural; ejerce una profunda y sostenida influencia en las actitudes sociales generales y en el pensamiento intelectual en la China moderna. Para muchos académicos, sobre todo aquéllos de las generaciones más viejas, pareciera "natu- ral" no sentir ninguna necesidad ni urgencia de estudiar a otros pueblos y culturas.

Por otra parte, no obstante, en tiempos premodernos, alrededor de mediados y finales del siglo XIX, China sufrió la derrota y semicolonización de los imperios europeos, y estuvo sometida a la hegemonía de Occidente hasta 1949. Por consiguiente, los intelectuales chinos están influidos por la opinión eurocéntrica y occidental colonialista de ver a China como una colonia, como un "otro" que debe ser estudiado. En conjunto, las actitudes aparentemente conflictivas del sinocentrismo y del eurocentrismo forman una paradoja compleja. Sin embargo, son sólo las dos caras de la misma moneda del etnocentrismo. Ambos han contribuido a la formación de la etnomusicología nacionalista contemporánea en China.

En cuanto a la situación de Taiwán, vale la pena mencionar otro factor. El Movimiento Independentista de Taiwán ha existido desde hace mucho tiempo en la isla. En las últimas décadas se ha vuelto más poderoso gracias al apoyo enérgico del Partido Democrático Progresista, que ganó el poder en el gobierno de Taiwán en la década de 1990. No es de sorprender que recientemente se haya for- talecido la tendencia de los estudios etnomusicológicos a enfocarse a la música local taiwanesa. Tal estudio está ayudando a construir la identidad nacional de Taiwán, distinta de la identidad china general.

\section{¿QUÉ HAY EN UN NOMBRE? EL MEOLLO DEL DEBATE EN LOS AÑOS OCHENTA}

A finales de la década de 1970, el gobierno de la RPCh empezó a aplicar lentamente una nueva política económica de "puerta abierta", y poco a poco la China continental se volvió accesible al resto del mundo. De conformidad con esta tendencia, el término inglés "etnomusicología", así como los conceptos asociados, se introdujeron en la RPCh por primera vez. En aquel entonces los datos se obtenían oralmente de unos cuantos músicos, compositores y académicos visitantes del Occidente, así como de algunas publicaciones en inglés incidentalmente disponibles. Pero esta información, si bien escasa, pronto causó un gran impacto en la comunidad de investigadores musicales en la RPCh, que había estado aislada del mundo académico exterior durante treinta años. Inspirados por los novedosos pensamientos de Occidente, los académicos empezaron, en la década de 1980, a discutir con entusiasmo algunos temas metodológicos respecto a la etnomusicología incluyendo: 1) la traducción china del término inglés "etnomusicología", 2) la definición y el alcance de la etnomusicología, 3) si el estudio que ya existía en China debía etiquetarse como "etnomusicología”, y 4) si el estudio en China debía seguir los enfoques y la dirección de la etnomusicología occidental.

Como se mencionó antes, esta discusión llevó luego a una visión compartida de que el estudio en China sí representa la versión china de la etnomusicología, y al acuerdo entre la mayoría de los académicos de que la etiqueta de "etnomusicología" era adecuada. Hubo desacuerdos sobre la mejor traducción china del término "etnomusicología", y muy pronto este punto se volvió el tema central del debate durante la década de 1980 . No se trata de un simple asunto de traducción de idiomas. De hecho, refleja la comprensión por parte de la comunidad académica china del concepto, alcance, objetivos, enfo- 
ques y dirección de la etnomusicología. Por ende, los académicos chinos se tomaron el debate en serio.

En chino convencional no existe la palabra equivalente al término inglés "Ethnomusicology" ("etnomusicología”). Hasta la década de 1980, tal estudio en China se denominaba "estudio de la música tradicional/popular" o "teoría de la música nacional". Por lo tanto, hacía falta acuñar un nuevo término chino para traducir "etnomusicología”. Entre varias propuestas el termino minzu yinyuexue fue considerado el mejor y desde entonces ha ganado aceptación duradera. A la vez, no obstante, algunos académicos construyeron el término zhongguo yinyuexue, que significa literalmente "musicología china". Ellos dicen que se presupone que el alcance de la "musicología china" incluye "todas las materias de la musicología general además de las materias particulares a la música china", y proponen "sustituir el concepto de etnomusicología por el concepto de musicología china" (Wei, 1985). Las razones principales para hacer esto son: 1) es un hecho que el énfasis del estudio en China siempre ha sido la música china, entonces el nombre "musicología china" le favorece más, y 2) su noción de "musicología china” es incluyente, no rechaza el concepto de "etnomusicología"; más bien incluye el estudio de todas las materias de la (etno)musicología. Desde entonces el nombre y la idea de la "musicología china" han ganado mucho reconocimiento y aceptación en China, compitiendo en popularidad con el término minzu yinyuexue. Pero en este debate nadie ha prestado atención a los siguientes dos asuntos, que yo considero importantes:

1. En el término minzu yinyuexue es claro que la palabra yinyuexue significa literalmente "musicología", pero la primera palabra minzu es muy ambigua y problemática. No es una palabra del idioma chino convencional, sino una palabra moderna acuñada a mediados del siglo XX, que de modo ambiguo presenta los conceptos de "nación(es)" o "pueblo(s)", pero que también ha sido empleada por los académicos chinos para traducir el término inglés para "grupo(s) étnico(s)". Mientras que en el uso chino implica una noción de categorías raciales fijas, los académicos fuera de China actualmente han llegado a considerar la etnicidad como algo fluido, situacional y cambiante. Por ende, minzu es muy distinto a lo que significa en inglés el término "grupo étnico" y no puede considerarse como el equivalente chino. En Occidente, los antropólogos interesados han planteado este asunto y lo han discutido intensamente (p. ej., David Y. H. Wu, 1990 y Harrel, 1990). Dicha preocupación la introduje en China (1997a, 1997b, 1998a), y en los últimos años muchos antropólogos también han empezado a tener cuidado cuando usan la palabra min$z u$. En el campo de la etnomusicología china, no obstante, este tema aún no ha llamado mucho la atención. Respecto al concepto chino de minzu, el término minzu yinyuexue, de hecho, implica un concepto de "musicología nacional (china)”. Por tanto, en realidad, es una forma disfrazada del otro término propuesto, zhongguo yinyuexue (musicología china). Evidentemente, es inadecuado usar "nacional (chino)" o "chino" para definir el estudio incluyente de la etnomusicología. Dicho uso refleja la fuerte actitud de nacionalismo chino o sinocentrismo. Los etnomusicólogos chinos dicen que están luchando contra el eurocentrismo, pero en este caso, inconscientemente están usando el sinocentrismo como el arma de su lucha.

2. En ambos términos, minzu yinyuexue y zhongguo yinyuexue, "música" y "musicología” (yinyuexue) están claramente indicados, en tanto que "cultura" y "antropología” no lo están. Esto refleja una tendencia en los estudios etnomusicológicos en China: el estudio se lleva a cabo más en términos de musicología que de antropología. En otras palabras, se estudia la música como música más que como cultura. Discutiré esta tendencia más a fondo en otra sección.

Desde mediados de la década de 1990, por medio de mis publicaciones en China he promovido otro término —yinyue renleixue - como una mejor traducción para "etnomusicología” (p. ej., 1997b, 1998a, 2000c). Literalmente significa "antropología de la música" o "antropología musical”. Este término ha ganado más y más aceptación en China. Me parece que comparado con las otras propuestas, se adapta mejor a lo que se supone que es la "etnomusicología". Al menos no tiene los problemas mencionados más arriba. 


\section{NACIONALISMO VERSUS OCCIDENTALIZACIÓN: EL MEOLLO DEL DEBATE EN LA DÉCADA DE 1990}

El debate sobre el término chino para "etnomusicología" se desvaneció a principios de la década de 1990 y empezaron a predominar otros temas, entre ellos el que se refiere a "la relación entre China y Occidente en la música”. Fue una discusión mucho más intensa que aquélla sobre la terminología en los años ochenta, y de hecho, se volvió el debate más acalorado de todo el siglo XX en la comunidad china de los estudiosos de la música.

Los temas claves de la discusión eran: ¿hacia dónde debe ir la música china?, ¿debe el desarrollo de la música china seguir su propio camino o debe seguir el camino del desarrollo de la música occidental de "alta cultura"?, ¿qué ha pasado hasta ahora respecto a la dirección del desarrollo de la música china en el siglo XX?, ¿qué debemos aprender de ello y qué debemos hacer al respecto ahora?

De hecho, éste es un nuevo debate sobre temas viejos. La misma discusión ya se había suscitado entre los aca-
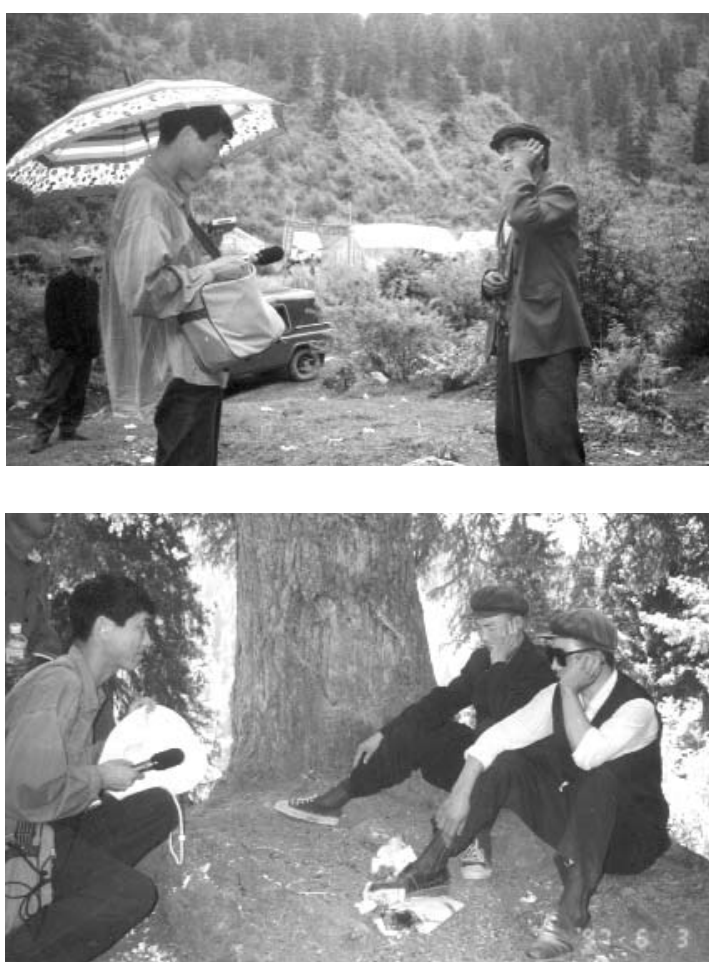

El autor, al lado izquierdo de las fotos, realiza estudio de campo en Gansu, noroeste de China, en junio de 1997.

al pensamiento chino sobre la música de ser conservador, fuera de época y retrasado; declaraba que los chinos debían "clamar por inspiración" y aprender de Occidente y del pensamiento occidental respecto a la música. Sin embargo, lo extraordinario es que lo que este bando denominaba "música de Occidente y pensamiento occidental respecto a la música" era en realidad arte/música clásica occidental y el pensamiento al respecto; excluía a la música folclórica, la música popular, el world beat y demás pensamiento e ideología relevante contemporáneas occidentales. En gran medida, considero todo este debate como el reflejo del nacionalismo versus la occidentalización en el campo de la música en China.

Hacia finales de la década de 1990 este debate, que duró diez años, finalmente llevó a la conferencia de noviembre 1998 en Beijing, celebrada en el Conservatorio Central de la Música. Llamada "Repaso y replanteamiento del camino del desarrollo de la música china en el siglo XX", la conferencia se celebró específicamente en torno a este 
debate. Asistieron más de ochenta académicos interesados, incluyendo a algunos de Hong Kong y de ultramar. Los participantes no leyeron ponencias preparadas como sucede en la mayoría de esos encuentros, sino que se turnaron para debatir y pronunciar discursos. En el mío expresé mi preocupación principal: que este debate se trataba de un problema de pragmatismo político - situación que discutiré más en la siguiente sección-.

¿Por qué los académicos en China, incluyendo a los etnomusicólogos, están tan obsesionados con esta discusión? La comunidad china de académicos de música parece no haberse dado cuenta, y menos ha podido deshacerse, de la interferencia del pragmatismo político en sus estudios. La creencia común entre ellos es que uno de los propósitos principales de los estudios de música es guiar el desarrollo de la música china en una dirección correcta y "sana". Los etnomusicólogos chinos consideran que esto es su obligación. Nadie ha impugnado esta opinión y anunciado que no es la responsabilidad del etnomusicólogo guiar el desarrollo de la cultura musical de la sociedad. Estudiamos música y su desarrollo, pero no es nuestro trabajo guiar el desarrollo de la música en lo que creemos es la dirección "correcta”. Las direcciones de tal desarrollo son discursivas y no existe algo como la "dirección correcta” que debe seguir la música. En el debate hay muchos juicios de valor implícitos en las opiniones de ambos bandos. Los dos creen que su manera es la "correcta" y "sana" para que siga el desarrollo de la música china. Pero, ¿cuál norma debe emplearse para hacer el juicio? ¿Existe alguna norma neutral y no prejuiciada o una "verdad" absoluta a este respecto? ¿Es necesario que haya una respuesta en blanco o negro sobre esto? Al reflexionar profundamente debemos concluir que el debate en sí es problemático y quizá ni siquiera valga la pena.

\section{CONFUCIANISMO, PRAGMATISMOY MARXISMO: ETNOGRAFÍA CHINA DE LA MÚSICA}

Una de las tres áreas principales del estudio etnomusicológico en la RPCh es lo que denomino la "etnografía mar- xista de la música al estilo chino". Para entender lo que es y por qué se ha convertido en un área principal de estudio, tenemos que examinar sus tres componentes principales: la profunda influencia de la tradición de Confucio, el enfoque gubernamental del marxismo clásico y el pragmatismo políticamente motivado.

\section{El caifeng confucianista como trabajo de campo}

Con una historia de 2500 años, el confucianismo es una tradición profundamente arraigada en China. A lo largo de este periodo, los intelectuales chinos mantuvieron la tradición de recolectar y registrar los textos de las canciones populares. Esta práctica se conoce como caifeng, que significa "recolección de canciones populares". Resulta evidente que ésta es una práctica que puede beneficiar mucho al estudio etnomusicológico hoy en día. Tradicionalmente, sin embargo, el propósito fundamental del caifeng fue registrar y conservar los textos de las canciones populares para la apreciación literaria y la inspiración, no para el estudio o la investigación en un sentido antropológico moderno.

La primera antología de poesía china, el Shi Jing (para una traducción al inglés, véase Shi Jing, 1996), que se cree fue compilada por Confucio (551-479 a.C.), incluye una gran cantidad de canciones populares obtenidas de la actividad caifeng de los intelectuales chinos de aquel entonces. A lo largo de la historia, los literatos chinos han encontrado inspiración para sus composiciones literarias o poéticas en las rimas populares. En épocas posteriores la actividad caifeng se extendió para incluir a la literatura y las costumbres populares, sobre todo aquéllas de las lejanas regiones rurales. Se ha vuelto una práctica popular y útil entre periodistas, escritores, artistas, compositores y actores, quienes usan dicho material popular para sus composiciones y actuaciones. Durante las décadas de 1920 y 1930 algunos académicos dedicados al estudio de la literatura popular, incluyendo los textos de las canciones populares, fomentaron vigorosamente la actividad caifeng. Siguiendo su ejemplo, los académicos chinos de música también han adoptado esta actividad para su estudio de la música popular, y sobre esta base se ha forjado 


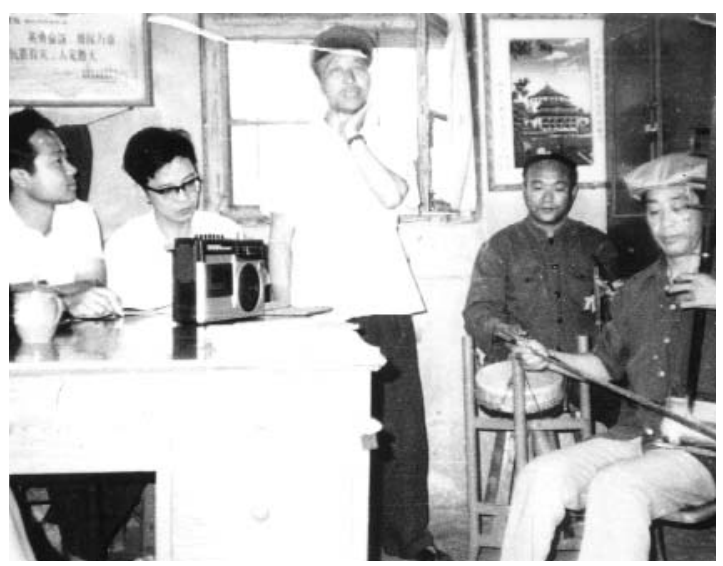

Dos miembros del equipo de caifeng del Conservatorio Nacional de Música graban a un músico tradicional en Tangshan, ciudad que está a unos 200 kilómetros al este de Beijing; agosto de 1982.

y desarrollado un estilo chino de etnografía de la música. Sin embargo, el caifeng no debe entenderse como equivalente al contemporáneo estudio de campo antropológico. Como práctica antigua, carece de teoría e interés antropológicos.

En la actualidad todos los etnomusicólogos chinos están de acuerdo, en teoría, en que durante el estudio de campo deben investigarse todos los factores socioculturales relevantes a la música. Sin embargo, de hecho, la mayoría de ellos en esencia hacen caifeng a modo de estudio de campo, como si no hubiera diferencia entre estos dos tipos de práctica. Por consiguiente, no sorprende que hasta ahora la mayor parte de las publicaciones de etnografía de la música chinas sólo comprenden transcripciones de música y textos de canciones, quizá algunas descripciones del aspecto musical; por lo tanto, la información proporcionada resulta insuficiente o escasa.

\section{Marxismo y pragmatismo político como pautas}

Hacia finales de las décadas de 1930 y 1940, entre los estudiosos de la música en el entonces territorio ocupado comunista de Yan'an, la actividad caifeng empezó a mezclarse con el marxismo clásico y el pragmatismo político. Desde 1949, este tipo de práctica combinada se extendió rápidamente en la RPCh y se volvió el tipo dominante de etnografía de la música en toda la nación. Sólo en los últimos años ha empezado a ponerse en tela de juicio.

La Constitución de la RPCh claramente estipula que la ideología gobernante en el país es el marxismo. Este principio ciertamente se hace cumplir en los estudios académicos. En otras palabras, todos los estudios e investigaciones académicas están obligados a seguir el enfoque marxista. Más aún, desde 1950 hasta finales de la década de 1970 la RPCh mantuvo sus puertas firmemente cerradas al intercambio con el exterior, inclusive a los contactos académicos. Detrás de la "cortina de bambú", durante todo ese periodo, los teóricos y académicos ignoraban los nuevos desarrollos teóricos, incluso en teoría marxista, del mundo exterior. Por lo tanto, lo que se siguió en la RPCh durante ese periodo fue en realidad marxismo clásico - la teoría que los comunistas chinos aprendieron antes de 1949 del régimen soviético leninista-stalinista—. Fuera de China, actualmente, la escuela marxista de antropología se ha desarrollado y actualizado enormemente. La teoría clásica y el pensamiento marxistas, tales como el evolucionismo social unilineal de Engels-Morgan, han caído en descrédito. Sin embargo, en la RPCh, el único marxismo que se conoció hasta la década de 1980 fue el clásico. El viejo enfoque marxista siguió dominando los estudios en el campo de la antropología general hasta mediados de 1990; y en el campo de la etnomusicología su dominio incluso continúa hoy en día.

El enfoque marxista clásico dominante en los estudios académicos de la RPCh se construye sobre el pragmatismo político. Esto es particularmente evidente en las ciencias sociales y las humanidades. El Partido Comunista Chino presta máxima atención a la propaganda y al control ideológico comunistas. Las artes están entre las áreas más afectadas por las políticas del Partido. Como he dicho (1994), en este campo el Partido y el gobierno han aplicado la norma de que "las artes deben servir a la política proletaria", quid del discurso de Mao Zedong en el Foro de Literatura y Arte en 1942, en la capital comunista de Yan'an (Mao, 1980 [1942]). Esta pauta también se ha aplicado a la investigación académica en las artes, incluyendo a la etnomusicología. Cualquier académico que se oponga a esta línea corre un riesgo que, en casos 
extremos, puede significar el fin de su carrera académica. Desde principios de 1980, esta situación se ha relajado hasta cierto punto, aunque el poder de esta pauta sigue siendo fuerte. En un intenso análisis teórico de la música contemporánea en la RPCh, un etnomusicólogo chino señaló el efecto negativo de la misma en la creatividad e investigación musical (Dai, 1987). Sin nombrar específicamente a Mao o señalar explícitamente su discurso en el Foro de Yan'an, el análisis de Dai es una fuerte y convincente crítica implícita de ello. Sin embargo, su artículo se enfrentó inmediatamente a una furiosa crítica por parte de algunos teóricos marxistas clásicos chinos de línea dura (p. ej. Xiao Xing, 1989 y Li Yedao, 1990). Desde entonces, el artículo de Dai ha sido la primera y única publicación en China que haya criticado el discurso de Yan'an.

El pragmatismo político no es nuevo en China. Se puede rastrear hasta la tradición profundamente arraigada del confucianismo. En la ideología confucianista, la música se considera no como mero entretenimiento sino como una herramienta que sirve a los propósitos políticos y educativos de las autoridades. En tiempos antiguos, la música servía en eventos tales como los ritos y las ceremonias político-religiosas que simbolizaban, aseguraban e intensificaban el poder empírico. La música formaba parte de las habilidades esenciales que debían dominar los funcionarios, las elites sociales y los intelectuales. Se estudiaba la música para garantizar su mejor manipulación como herramienta política y educativa, al servicio del sistema imperial. En la China contemporánea el Partido Comunista Chino ha adaptado el confucianismo a sus propios fines. Como muchos otros aspectos de la tradición confucianista, el pragmatismo político de la música se ha tomado por hecho. Como se demostró en el citado caso del debate durante la década de 1990, el pragmatismo político está tan profundamente implantado en el pensamiento intelectual chino que muchos académicos contemporáneos lo practican de forma "natural" y nunca tienen la menor duda de que sus pensamientos y actitudes están influidos por ello.

Con dicha tradición cultural, clima social y situación política, la etnografía de la música de corte marxista clásico al estilo chino tomó forma y se ha vuelto dominante.
Cuando se registran o transcriben datos de campo esta etnografía está políticamente prejuiciada. En la selección de la música a estudiar, los criterios son marxistas clásicos y la descripción de la etnografía debe corresponderse con las pautas marxistas. La metanarrativa y gran teoría marxistas, tales como la teoría evolutiva sociocultural unilineal, se siguen estrictamente como norma. La teoría marxista es "la verdad" y no debe ponerse en duda, y el trabajo de campo, la investigación y la etnografía sólo sirven para acumular más evidencia y demostrar el absoluto acierto de esta "verdad". Por ejemplo, las canciones populares con textos que critican al Partido nunca deben elegirse para investigar y registrar; ni debe hacerse con ningún fenómeno social o información relacionada con dicha canción. En esta etnografía muchos pueblos minoritarios en China han sido catalogados como "primitivos" porque sus sociedades y culturas se consideran en la fase de "sociedad primitiva" o "sociedad esclavista" en la escala evolutiva, hasta que el Partido Comunista Chino los "liberó" y ayudó a "saltar" al nivel de "sociedad socialista".

\section{ANTOLOGÍA DE LA MÚSICA NACIONAL COMO UN RESULTADO IMPORTANTE}

El resultado más notable y típico de esta etnografía de la música es un enorme proyecto: la Antología de la música $y$ danza populares chinas. A inicios de la década de 1960, la Asociación de Músicos Chinos, el Instituto de Investigación de Música Nacional y la Editorial de Música del Pueblo, en colaboración, iniciaron un vasto proyecto en todo el país: reunir, registrar, transcribir, compilar y publicar una enorme serie llamada Antología de la música popular china. Debía comprender treinta volúmenes para abarcar las entonces treinta provincias, regiones autónomas y municipios del gobierno central. El proyecto fue interrumpido por la "Revolución Cultural", pero se retomó en 1979.

En ese año el gobierno de la RPCh aprobó un proyecto más grande y desarrolló uno más ambicioso: la Antología de la música y danza populares chinas. Dicho proyecto está patrocinado y apoyado por el gobierno, y cuenta 
con ayuda financiera adicional por parte de la UNESCO. Está diseñado como una enorme colección que busca abarcar todas las categorías de la música y danza tradicionales chinas. La serie está dividida en seis categorías: canción popular, canto narrativo, música instrumental, bailes populares, música teatral y etnología del teatro. Cada categoría está representada en 31 tomos, una por región (incluyendo la recientemente establecida provincia de Hianan). De hecho, muchos tomos comprenderán dos subtomos debido a la gran cantidad de transcripciones que se incluirán. Por consiguiente, en total se publicarán varios cientos de enormes tomos. Desde 1979, el trabajo de la Antología... es una tarea principal en el campo de la etnomusicología en la RPCh. Ya se han publicado varios tomos, pero completar la serie tardará algunos años. Sin duda, éste es un trabajo de recolección, clasificación, transcripción y publicación de la música y danza populares, más no de estudio, análisis e investigación.

Como se mencionó con anterioridad, la etnografía de la música en China está, en general, políticamente prejuiciada. La Antología... no ha escapado del control de las pautas marxistas y del pragmatismo político comunista. A pesar de los desacuerdos y las discusiones por parte de algunos académicos, las autoridades responsables establecieron las políticas editoriales para la Antología... y los criterios de selección de las piezas musicales que se incluirían en ella. Naturalmente, tanto la política como los criterios siguen la pauta marxista; se estipula que la prioridad de la Antología... es servir a la política comunista más que a la investigación académica. Por lo tanto, el producto final estará políticamente prejuiciado y, hasta cierto punto, será académicamente engañoso. Por ejemplo, las canciones populares que critican o desafían la autoridad del Partido, o las canciones que violan la norma moral comunista (p. ej. aquéllas con referencias sexuales) están excluidas de la Antología..., mientras que las canciones que alaban al Partido y gobierno están representadas en exceso. En uno de mis artículos (1994) hay ejemplos específicos, análisis y discusión.

En años recientes, siguiendo el mayor fortalecimiento por parte del gobierno de su política de puerta abierta y en preparación para unirse a la Organización Mundial de
Comercio y ser anfitriones de las Olimpiadas 2008, el clima social y político en la RPCh se ha relajado. La ideología clásica marxista ha seguido aflojando su control sobre la sociedad en general y los estudios académicos. Los políticos y académicos liberales sigilosamente han ganado mayor influencia. Por ende, en los posteriores tomos de la Antología..., sobre todo aquéllos en los cuales la edición final y publicación se hizo después de 1995, es evidente que dicha interferencia política ha cedido hasta cierto punto. No obstante, en esencia, la Antología... aún no se ha desviado de la trayectoria establecida por la ideología comunista china.

Los tomos de la Antología... publicados hasta ahora ya constituyen la colección más grande y completa de su tipo jamás producida en China. De hecho, cuando esté terminada, es probable que la Antología... sea el compendio de música y danza más grande del mundo. Debemos reconocer este enorme logro e importante éxito en el campo de la etnomusicología. Quizá un trabajo tan grande que abarca toda la nación sólo podría lograrse en un país como la RPCh, con el pleno apoyo de un gobierno centralizado que tiene poder absoluto sobre todas las autoridades de provincia. Por otra parte, sin embargo, debido a los elementos negativos mencionados antes, también debemos estar concientes de las deficiencias en las transcripciones y la información ofrecidas en la Antología... tocante a la autenticidad, representatividad y confiabilidad.

\section{MUSICOLOGÍA VERSUS ANTROPOLOGÍA: ESTUDIO HISTÓRICOY MORFOLOGÍA DE LA MÚSICA}

Regularmente, la etnomusicología se considera como una rama de la antropología. No obstante, dentro de la disciplina de la etnomusicología siempre han existido dos corrientes marcadas: la musicológica y la antropológica. Aunque no siempre están forzosamente en oposición, estas dos corrientes sí tienen puntos centrales, intereses y enfoques distintos y a veces contrarios. Al examinar la situación en China, vemos claramente que hasta ahora la tendencia dominante en la etnomusicología ha sido la musicológica, si bien durante la última década se 
han adoptado cada vez más las aproximaciones antropológicas.

Hasta donde sé, es probable que todos los etnomusicólogos en China tengan antecedentes musicales o musicológicos más que antropológicos. La mayoría de ellos, sobre todo los de las generaciones más viejas, tienen poco contacto con la comunidad antropológica. Durante mucho tiempo en China los etnomusicólogos y los antropólogos han sido dos comunidades separadas; cada una se ocupa de sus propios asuntos y casi nunca tienen intercambios o cooperación entre sí. A los estudiantes del campo de la etnomusicología no se les pide leer publicaciones antropológicas. A su vez, los antropólogos por lo general no contribuyen a la investigación y publicación de la etnomusicología. Esto es bastante diferente de lo que sucede en Occidente, donde una proporción considerable de etnomusicólogos son antropólogos plenamente entrenados y calificados, o al menos tienen algún tipo de antecedente o experiencia antropológica, y el estudio etnomusicológico se mantiene a la par de los desarrollos y teoría antropológicos. Por tanto, no es de sorprender que la tendencia musicológica domine en la etnomusicología en China.

\section{ESTUDIO HISTÓRICO UNILINEAL DE LA MÚSICA}

En China el estudio histórico de la música nacional está bastante avanzado. Desde la década de 1950 se ha investigado intensamente en este campo y se han obtenido grandes resultados. Éstos incluyen: estudios históricos de determinados tipos de instrumentos musicales (p. ej. Zhuang, 1972); historia general de la música china antigua (p. ej. Yang Yinliu, 1981); estudio de la teoría de composición antigua (p. ej. Xia, 1982); análisis de manuscritos de música antigua (p. ej. Ye, 1982); investigación de descubrimientos arqueológicos particulares (p. ej. Niu, 1985); interpretación de notaciones antiguas (p. ej. Chen, 1988); estudio de antiguas teorías de temperamentología —acústica de la música— (p. ej. Zhao, 1993), y trabajos que versan sobre muchos otros temas. Existen al menos tres razones para un desarrollo tan intenso:
1. Con más de cinco mil años de civilización continua, los recursos materiales de China para la música son excepcionalmente ricos. Por ejemplo, un gran número de géneros musicales y tipos instrumentales actuales tienen una historia que va desde cientos hasta miles de años; muchos especímenes de antiguos instrumentos musicales fabricados hace cientos o inclusive uno o dos mil años se han conservado bien, algunos de ellos hoy en día están en uso; y constantemente se hacen descubrimientos arqueológicos muy abundantes.

2. Desde la época de Confucio en el siglo V a.C., los intelectuales han mantenido una fuerte tradición de estudiar la música china. A diferencia de lo que sucede en muchos otros países en China a lo largo de los últimos 2500 años se ha desarrollado un sistema muy complejo e intensivo de teoría de la música, que comprende teorías de estética, temperamentología y morfología. Los recuentos escritos en estos campos son abundantes y presentan una acumulación continua de escritos académicos que empiezan desde las antiguas escuelas filosóficas confucianista, taoísta y mohísta. Esto ofrece un terreno fértil para el estudio relevante e investigación en tiempos modernos.

3. En la RPCh el estudio de los "dinosaurios" es comparativamente irrelevante para la actual política y por ende es tema de menor interferencia de la política e ideología comunista. Así, los académicos en esta área de estudio tienen mayor libertad y menor riesgo político. Como he señalado (1994), en el clima político opresivo de la RPCh, sobre todo durante el periodo que va de 1950 hasta principios de la década de 1980, los académicos tendieron a evitar las áreas de estudio políticamente riesgosas y prefirieron los terrenos más seguros. Por consiguiente, la investigación histórica se volvió su área favorita. No obstante, esta situación comparativamente libre no significa que en la RPCh el estudio histórico esté exento de la influencia política y que sea independiente de la interferencia y control de las autoridades.

Los enfoques seguidos en el estudio histórico de la música pueden categorizarse en unos cuantos grupos como se describe a continuación: 
1. Estudio de textos antiguos al viejo estilo, tal como obtener y resumir la información histórica mediante la interpretación y explicación de textos encontrados en los escritos antiguos. En China, éste es un enfoque común que se sigue en los campos del estudio histórico, si bien no es el dominante.

2. Un estudio más completo, combinando el método de análisis textual con el examen de situaciones relevantes durante el(los) periodo(s) histórico(s) en cuestión, comprendiendo aspectos de literatura, filosofía y estética, sobre todo al usar información encontrada en fuentes históricas escritas o materiales disponibles, incluyendo los hallazgos arqueológicos. La investigación de dichos aspectos sigue el enfoque musicológico tradicional más que el antropológico, y mucho menos los enfoques multidisciplinarios desarrollados en Occidente tales como los métodos de estudios culturales.

3. Muchos académicos sólo prestan atención a la música "pura” en sí. Su interés se centra únicamente en la morfología. Abundaré al respecto en la siguiente sección.

4. En la RPCh, bajo las pautas políticas mencionadas arrimo social unilineal de Engels-Morgan, debe, cuando es relevante, aplicarse para explicar los fenómenos y desarrollos históricos. La recolección de datos y el análisis están, por consiguiente, políticamente prejuiciados. Los fenómenos y desarrollos que parecen corresponderse a la gran teoría marxista o al evolucionismo unilineal son tomados como prueba de la teoría, en tanto aquellos que se desvían de la órbita marxista se marginan o simplemente se ignoran.

5. Desde principios de la década de 1980 han surgido algunas nuevas tendencias e intentos para aplicar enfoques alternativos. Discutiré éstos más adelante en el artículo.

\section{MORFOLOGÍA ESTRUCTURALISTA DE LA MÚSICA}

Tocante a los temas particulares que abordaré en esta sección, aquellos lectores que no están familiarizados con los hechos étnicos de China requieren de información

sucinta primero. De la población actual de China de casi 1.4 mil millones de habitantes, la enorme mayoría -el $94 \%$ - son chinos han, mientras que los restantes $84 \mathrm{mi}$ llones se conforman de varios pueblos minoritarios. El gobierno ha reconocido oficialmente a 55 grupos minoritarios en el país. Como señalo más adelante, en China tanto el estudio histórico de la música como la morfología de la música son, en gran medida, de naturaleza etnocéntrica; específicamente son han-céntricas.

La así llamada "morfología de la música" es un enfoque pura o primordialmente musical con poca o ninguna referencia a los elementos socioculturales. En China, hasta el día de hoy, la morfología sigue siendo un vasto y fuerte campo de la etnomusicología. Al igual que sucede con los estudios históricos de la música, la mayoría de los académicos en la RPCh evitan las áreas políticamente riesgosas y prefieren el terreno más seguro de lo "puramente musical”. Por consiguiente, allí la morfología de la música se ha vuelto un campo de estudio "naturalmente" popular.

En el estudio morfológico, la música no se trata como cultura o fenómeno social sino que se examina en términos pura o primordialmente técnicos. Esto incluye el estudio de la temperamentología, la escala, el modo, la forma, el estilo, la estructura melódica, la estructura armónica, la textura, la orquestación, los textos de las canciones, la relación mecánica entre el texto-canción y la melodía, la familia de tonada, los rasgos regionales de la música, la clasificación de la música, así como la relación morfológica entre la música de distintas regiones y entre géneros musicales diferentes. Incluso durante la década de 1950 y principios de la de 1960, tales estudios ya habían alcanzado mucho, con numerosos trabajos de investigación publicados y varias teorías establecidas. Este estudio se detuvo con la "Revolución Cultural", pero se retomó a finales de los años setenta y se ha desarrollado más desde entonces, siguiendo los pasos establecidos anteriormente. Existen unos cuantos tipos de trabajo y logros en este campo dignos de mencionarse aquí.

Quizá el logro más exitoso se halla en el estudio de la temperamentología. Aprovechando la compleja teoría antigua y los ricos recursos materiales y escritos acumulados a lo largo de la historia, incluyendo los hallazgos arqueológicos, los investigadores chinos han resuelto varios 
misterios o enigmas que quedan en la teoría antigua y han avanzado hacia el establecimiento de un sistema teórico contemporáneo de temperamentología (p. ej. Zhao, 1993 y Li Mei, 200ob). Los académicos más notables en esta rama incluyen a Yang Yinliu, Huang Xiangpeng, Miao Tianrui, Zhao Songguang y Li Mei, quienes son los sucesores del investigador pionero Wang Guangqi.

En la creencia de que la teoría occidental para el análisis y la composición musicales eran inadecuadas para la realidad china, desde la década de 1950 muchos académicos han tratado de establecer un sistema teórico chino para estos fines, que versa sobre el modo musical, la forma, el contrapunto, la armonía, la textura, la orquestación, etc. No obstante, a pesar de las mejores intenciones, la mayor parte de dichos intentos hasta ahora, en esencia, han seguido el enfoque o principio de la teoría de la música clásica occidental, si bien los teóricos chinos han inventado o adoptado términos en su idioma para su teoría "china”. Algunos ejemplos pueden encontrarse en el trabajo reciente de Du Yaxiong, Zhongguo Minzu Jiben Yueli [Teoría esencial de la música nacional china], 1995. Por otra parte, este trabajo es engañoso ya que presupone que las teorías establecidas sobre la práctica musical de los chinos han también pueden aplicarse a la música de los demás grupos étnicos de ese país. Tal conjetura es un buen ejemplo del han-centrismo mencionado con anterioridad, que no es infrecuente en el estudio de la música china.

Un logro mucho más convincente es el sistema teórico propuesto por Yu Huiyong, a principios de la década de 1960, y que versa sobre el modo, la estructura melódi$\mathrm{ca}$, la forma musical, el estilo y la relación entre las melodías y los textos de canciones. Dicha teoría está resumida y sustraída de la teoría y práctica musical popular y folclórica. Por motivos políticos, el estudio de Yu no fue publicado hasta 1997 (Yu, 1997 [1963]). ${ }^{3}$ Sin embargo, a

${ }^{3}$ Durante los últimos años de la "Revolución Cultural" Yu estuvo involucrado en actividades políticas y se volvió un miembro clave de la así llamada "Banda de los cuatro", encabezada por Jiang Qing, la difunta esposa de Mao Zedong. Tras la muerte de Mao en octubre 1976 Jiang y su "Banda de los cuatro" fueron arrestados; también lo fue Yu, quien se suicidó durante la detención antes del juicio programado. Desde entonces, nadie se atrevía a mencionar los logros académicos principios de la década de 1980, Yu enseñó su teoría en uno de los dos conservatorios más importantes de China, el Conservatorio de Música de Shanghai, y desde entonces sus detalladas notas de conferencia circularon entre los académicos y estudiantes relevantes y se tienen en alta consideración. Por consiguiente, aun antes de la publicación de su obra en 1997, la influencia de su sistema teórico no debe desestimarse.

Algunos estudios de morfología parecen ir más allá del alcance de la música "pura”. Además de la música en sí, los instrumentos musicales, las interpretaciones e incluso los intérpretes también se exploran. No obstante, tal estudio está aún muy limitado a las estructuras físicas, las formas y los elementos mecánicos o técnicos que se relacionan directamente con la música, en tanto que otros aspectos socioculturales casi nunca se tocan (p. ej. Gao, 1981 y Yuan Jinfang, 1999).

Por otra parte, algunos académicos chinos han tratado firmemente de establecer un sistema teórico de "armonía china" y aplicarlo a la composición. Entre ellos, el trabajo de Li Yinghai (1959) se ha vuelto un clásico. Sin embargo, al examinar tales teorías chinas de armonía resulta claro que su principio radica en una base de la teoría clásica de armonía occidental. Zhao Songguang también ha establecido una teoría del sistema de modo y armonía chinos, que él dice se basa en la temperamentología tradicional. Sin embargo, su monografía publicada sobre la teoría del sistema de modo chino sólo circuló en un tiraje corto (1964), y su teoría de la armonía china (enseñada en el Departamento de Composición del Conservatorio Central de Música en Beijing a principios de la década de 1980) parece demasiado compleja y difícil de entender aun para la mayoría de los compositores chinos. Por lo tanto, su teoría nunca ganó popularidad.

Las tentativas de establecer un sistema chino de armonía, en vez de adoptar el sistema occidental, pareciera una reacción contra el eurocentrismo. En el fondo, quizá sea justamente lo contrario - la psicología que subyace en esta práctica es en realidad eurocéntrica-. En esencia, la

de este "miembro contrarrevolucionario" sino hasta finales de los años noventa. 
música tradicional china han es monofónica. La esencia y belleza principal de esta música radica en la rica variedad de timbre y melodía lineal, no en la estructura vertical de progresiones armónicas. Pero los teóricos chinos no pueden encarar este hecho. Creen que la música monofónica está más abajo en la escala evolucionista de la cultura humana, mientras que la armonía representa un nivel más avanzado en la evolución sociocultural de la música.

En dos de mis artículos de reciente publicación (200ob, 2002) planteo y discuto algunos propósitos y problemas respecto a la morfología de la música china, propósitos que nunca antes se habían advertido en ese país. Por una parte, la morfología de la música china se ha construido sobre la base de criticar al eurocentrismo, rechazando la práctica de aplicar la teoría clásica occidental para analizar la música china. Por otra parte, no obstante, la morfología de la música china se ha construido bajo la influencia del estructuralismo y la metanarrativa modernista occidentales, con dos tendencias generales fundamentales: 1 ) aislar la música de todos sus antecedentes socioculturales y conducir un análisis musical "puro", y 2) tratar de teoría? En vista de que durante décadas los etnomusicólogos en otras partes han prestado atención a los aspectos socioculturales de la música, ¿deberían los morfologistas de la música china extender su foco y objetivo de análisis de música "pura" para abarcar también a las sociedades y las culturas? Y, después de todo, ¿ es factible encontrar una gran teoría para analizar a toda la música del mundo entero tal como los morfologistas de la música china han tradicionalmente soñado hacerlo?

\section{NUEVAS TENDENCIAS A PARTIR DE I980}

Aprovechando la política económica de "puerta abierta”, desde principios de la década de 1980, los académicos en la RPCh han podido obtener información y absorber ideas del mundo exterior, sin dejar sus proyectos en curso. La reforma económica también ha mejorado la condición financiera en la RPCh. Los institutos académicos y los individuos están en mejores condiciones de financiar sus actividades e intercambios académicos internacionales, tales como asistir a conferencias en otros países, visitar instituciones académicas extranjeras e incluso celebrar conferencias internacionales. Por tanto, más y más conceptos de la antropología contemporánea occidental se han introducido y discutido. Los académicos están más activos que nunca en busca de nuevos métodos de investigación e ideas. En el campo de la etnomusicología, los cambios más importantes durante este periodo incluyen los siguientes:

1. Una disminución lenta pero continua del control basado en las pautas y el enfoque marxistas. No obstante, aún hay mucho camino por recorrer antes de llegar a un grado razonable de independencia académica.

2. Un intento de ponerse al día respecto al mundo exterior, tras varias décadas de aislamiento.

3. Un replanteamiento del desarrollo de la etnomusicología en China durante el siglo XX en el afán de identificar y remediar las deficiencias y encontrar mejores enfoques de investigación.

4. Una expansión del alcance de la investigación. Los temas elegidos para el estudio y la investigación se han 


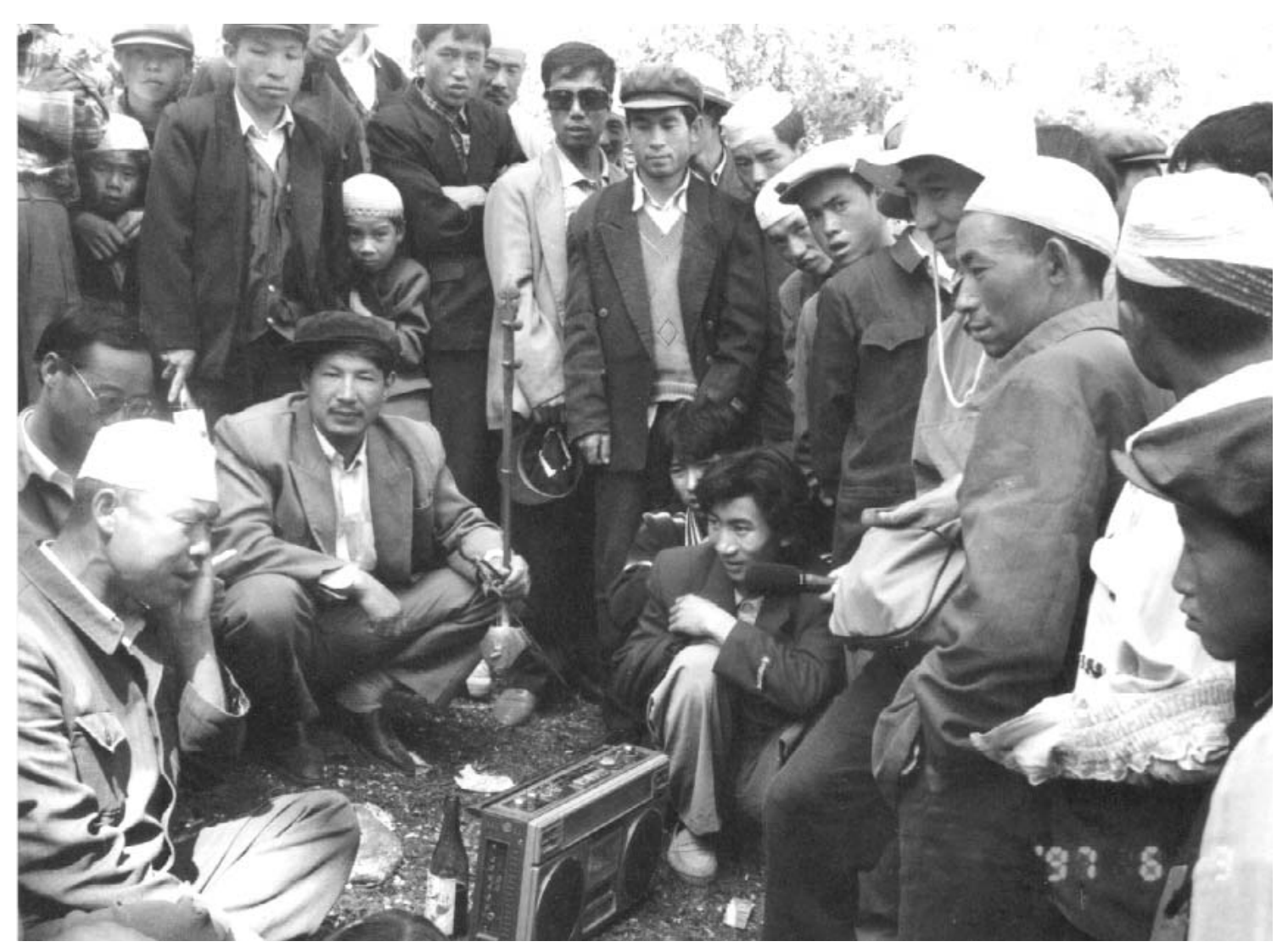

Yang Mu realiza estudio de campo en la montaña Songming Yan, provincia de Gansu (noroeste de China), en junio de 1997. El autor se encuentra entre el público, centro a la derecha, con una bolsa, un micrófono y una grabadora de mini $\mathrm{CD}$ en la mano, frente al cantante.

vuelto paulatinamente más variados. Algunos fenómenos y temas antes desatendidos o marginados han llamado la atención de los académicos. Tales adelantos han ido socavando poco a poco la dominación de los mencionados tres tipos principales de estudio de etnomusicología en China, es decir, de la etnografía de la música, los estudios históricos de música y la morfología de la música.

5. Una ruptura muy lenta pero positiva de la circunscripción a la música china en la disciplina.

6. Un creciente interés en la teoría contemporánea y las cuestiones teóricas.

7. Un creciente interés, sobre todo entre la generación más joven de académicos y estudiantes, en los enfoques antropológicos o multidisciplinarios en vez de los enfoques musicológicos convencionales.
Estos cambios han ocurrido muy despacio a lo largo de los últimos veinte años, pero todos han continuado firmemente. A fines del siglo XX, no obstante, la mayoría se han acelerado de manera significativa. A continuación agrupo la tendencia principal en dos grandes categorías.

\section{MAYOR INTERÉS EN LOS TEMAS TEÓRICOS Y ENFOQUES SOCIOCULTURALES}

El debate de la década de 1980 sobre el término y concepto chinos de "etnomusicología" llevó a publicaciones preliminares que versaron sobre el concepto general, el alcance, los objetivos, la historia, los enfoques y la metodología de la etnomusicología. En tales trabajos la discusión se condujo desde las perspectivas chinas, representando 
la comprensión de los académicos chinos de la etnomusicología. En mayor o menor medida, ésta difiere del entendimiento general, libremente unificado, de la práctica de la etnomusicología en Occidente. La diferencia se debe sobre todo a dos factores. Por una parte, hasta ahora la información obtenida por los académicos chinos acerca de la etnomusicología occidental ha sido insuficiente e inevitablemente han habido malentendidos e interpretaciones falsas. Por otra parte, en general, entre la comunidad académica china relevante se cree que la etnomusicología en China no debe ser una copia idéntica de lo que se practica en Occidente. Para China, los conceptos, enfoques, etc., deben ser aquellos que mejor se correspondan con su situación y por tanto es natural que se desvíen de los occidentales.

Hasta mediados de la década de 1980, dominados por el mencionado enfoque del estilo chino de etnografía de la música, se volvieron muy comunes los trabajos que simplemente describían las características de determinados tipos de música sin o con poco análisis teórico y discusión. Esta situación ha cambiado paulatinamente en los últimos años. Los trabajos que enfocan la discusión teórica y aquellos que combinan la etnografía descriptiva con el análisis teórico se han vuelto más numerosos. Algunos estudios recientes se desvían del planteamiento convencional musicológico y adoptan enfoques antropológicos, socioculturales o multidisciplinarios contemporáneos (véase por ejemplo Dai, 1991 y Yang Minkang, 1992).

En los últimos años, algunos antropólogos, sociólogos y filósofos chinos más jóvenes han introducido enérgicamente a China las teorías contemporáneas de las comunidades académicas internacionales. La mayoría de ellos tienen buen dominio de una lengua extranjera, o recientemente obtuvieron sus títulos de posgrado en disciplinas relevantes de universidades occidentales. Han aplicado tales teorías a su propia investigación de la sociedad y cultura chinas. Algunos de los resultados de sus investigaciones se publicaron en chino (p. ej. Wang Mingming, 1997; Guo, 2000; Naribilige et al., 2001). A fines del siglo $\mathrm{XX}$, algunos de estos estudiosos también tradujeron y publicaron trabajos de los académicos contemporáneos occidentales más influyentes, tales como Michel Foucault, Clifford Geertz, J. F. Lyotard, Jacques Derrida y Edward
Said. Comparado con este adelanto, el estudio de la etnomusicología en China se ha quedado atrás. En años recientes algunos etnomusicólogos chinos han traducido y publicado ciertos artículos occidentales contemporáneos que versan sobre la teoría y metodología etnomusicológica, pero la cantidad de estas traducciones está lejos de ser suficiente para satisfacer la creciente demanda en China. Aparte de dichas traducciones, existen pocos trabajos publicados que introduzcan la teoría contemporánea y hagan referencia específicamente a la situación china y al estudio de la etnomusicología, excepto una serie de mis propios artículos en chino publicados en los últimos años especialmente con este fin (p. ej. 1997a, 1997b, 1998a, 2000a, 2000b, 2000c, 2001 y 2002).

\section{EXPANSIÓNY EXPLORACIÓN DE LOS CAMPOS DE ESTUDIO}

En el campo de la etnografía de la música, la información de referencia a investigar ya no está limitada a los factores más obvia y directamente relacionados con la música. Las investigaciones ahora pueden extenderse a las vidas y gustos de la audiencia, la situación económica local, las conexiones con el extranjero, etc. Se investiga una gama de factores socioculturales más vasta. A la vez, más investigadores se han desviado efectivamente de la pauta políticamente prejuiciada y discriminatoria marxista, si bien ninguno de ellos ha declarado públicamente que lo está haciendo.

Hay algunos adelantos y logros notables en el estudio de la música religiosa. Hasta la década de 1980, el gobierno de la RPCh trataba toda religión como superstición y durante la "Revolución Cultural" toda actividad religiosa fue prohibida. Bajo estas circunstancias existía el estudio de la música religiosa sólo dentro del campo de los estudios históricos, donde era inevitable mencionarla puesto que formaba parte esencial de la vida en la China antigua. No obstante, desde principios de la década de 1970 el gobierno ha aflojado paulatinamente su política hacia la religión. Por consiguiente, la práctica religiosa ha florecido en la China continental, poniéndose a la par de Hong Kong y Taiwán, donde la actividad reli- 
giosa siempre fue popular. El estudio de la música religiosa pronto se desarrolló también (véase por ejemplo el informe de Tsao y Xue, 2000).

En el campo del estudio histórico de la música la nueva tendencia más sobresaliente es, también, la expansión de su alcance; esta tendencia surgió sobre todo en los años noventa. Hasta finales de la década de 1980, salvo un par de artículos breves y disertaciones menores, el tema del estudio histórico se había limitado a la música china en sí. Durante la década de 1990, al contrario, varios investigadores llevaron a cabo un trabajo sustancial más allá de estos confines geoculturales y publicaron sus hallazgos (véase por ejemplo Tao, 1994 y Feng, 1998).

El alcance del estudio histórico también se ha extendido a algunas áreas antes marginadas o desatendidas. El desarrollo más importante a este respecto es la investigación de la historia de las minorías étnicas chinas. Hasta fechas muy recientes, el estudio histórico de la música china se había limitado casi exclusivamente a aquella de la mayoría han. Durante décadas la así llamada "historia de la música china" de hecho fue la historia de la música china han, y nadie se había cuestionado seriamente esta práctica hasta finales de la década de 1990 cuando apareció el trabajo colectivo Historia de la música de las minorías étnicas chinas, editado por Yuan Bingchang y Feng Guangyu (1998). Además de estos adelantos, en la década de 1990 algunos académicos empezaron a prestar atención a los anteriormente desatendidos temas de género en el estudio histórico de la música china (p. ej. Xiu y Jian, 1993). No obstante, hasta ahora los estudios de género no han entrado a la corriente principal del estudio etnomusicológico en China.

En el campo de la morfología de la música, Shen Qia propuso una teoría sobre la estructura física de la nota musical y melodía de los chinos han (1982 y 1983). La teoría propone que existe una diferencia fundamental entre las estructuras de las notas musicales y melodías han chinas y las occidentales. Aquélla parece una curva continua, y es casi imposible separar las notas conectadas en el espectro; mientras que en la occidental tiene una forma clara, escalonada, en la cual cada nota tiene un nivel de tono estable y distinguible. Shen llama a la estructura de la música china yinqiang. Esta característica fundamental de la música china han significa que no puede analizarse usando la teoría de música clásica occidental. Shen propone un sistema de análisis para la música china han con base en esta característica. La teoría yinqiang de Shen es un importante adelanto en el campo de la morfología de la música china.

A finales de la década de 1990, la investigación de Li Mei sobre la temperamentología y el "tono neutral" (un tipo de nota cuyo nivel de tono cae entre aquéllos de dos semitonos sucesivos en una escala regular y cuyos atributos de temperamento van más allá de cualquier sistema de afinación conocido) ofrece una explicación convincente del fenómeno yinqiang desde un punto de vista científico (p. ej. 1998, 2000a, 2000b and 2001). Li también buscó darle un sentido sociocultural a su investigación científica, llevándola a cabo con referencias transculturales. Este esfuerzo indica un alejamiento del enfoque estructuralista moderno de análisis de la estructura musical "pura" dentro del estudio morfológico de la música.

Fuera de los campos convencionales de los estudios históricos y la morfología, vale la pena mencionar un novedoso estudio emergente. Hasta fechas muy recientes, la música popular contemporánea era firmemente rechazada por las instituciones y comunidades académicas de música en China. Pero durante la década de 1980, gracias a la política de "puerta abierta", un influjo de bienes occidentales tales como los casetes, discos compactos y equipos de sonido trajeron consigo una inundación de música popular estilo occidental. Esto incitó un acalorado debate entre los músicos y los académicos de la música en China. Hasta mediados de 1990, la opinión dominante en las comunidades académicas fue que tal música era un resultado no bienvenido del capitalismo occidental, que no era digno de estudio y que debía eliminarse completamente de la sociedad. Sin embargo, esta opinión tuvo adversarios y durante los últimos años finalmente ha perdido su dominio académico. El primer trabajo sustancial que impugna esta vieja visión fue presentado por un chino completamente desconocido para la comunidad de etnomusicólogos en China (Wang Yi, 1994). Este caso demuestra el fracaso de la comunidad etnomusicológica china a reconocer el estudio de esta música popular como estando dentro del alcance de la etnomusicología. 
Pronto le siguió otro estudio mucho más extenso y profundo, realizado por un bien conocido etnomusicólogo chino (Zeng, 1998). Si bien es posible que su trabajo no se considere novedoso fuera de China, dentro de ese país realmente ha establecido una nueva rama de estudio de la etnomusicología.

\section{COMENTARIOS FINALES}

Para concluir, se pueden hacer los comentarios siguientes:

En China el estudio etnomusicológico se desarrolló sobre todo durante la segunda mitad del siglo XX y ha progresado enormemente desde principios de la década de 1980. Los adelantos más sobresalientes incluyen ordenar y desarrollar la teoría de la temperamentología china, recolectar y registrar los abundantes materiales musicales tradicionales y populares, los hallazgos arqueológicos de música e instrumentos musicales antiguos y algunas nuevas tendencias desarrolladas en la década de 1990. Por otra parte, han habido deficiencias y problemas. Los más importantes pueden agruparse en cuatro aspectos: 1) la del mundo al final del siglo. Esto vale también para los avances en la investigación académica, incluyendo la etnomusicología. Con respecto a la teoría contemporánea del mundo exterior, la etnomusicología en China se encuentra aún más atrasada que otras disciplinas como la antropología social, la sociología y la filosofía. Ojalá que las nuevas tendencias progresistas que han surgido en años recientes sigan desarrollándose y ayudando a superar esas deficiencias. También se espera que la continua relación de la RPCh con la comunidad internacional haga disminuir aún más la represión política y, con el tiempo, se beneficie la investigación académica incluyendo el estudio de la antropología de la música.

\section{Bibliografía*}

Chen Yingshi, 1988, "Dunhuang Yuepu Xinjie" ["Nueva interpretación de los manuscritos musicales descubiertos en Dunhuang"], Yinyue Yishu [El arte de la música] núm. 1, pp. 10-17; núm. 2, pp. 1-4.

Confucio, 1996, Shi Jing [The Book of Songs] [Cancionero chino], trad. y ed. de Arthur Waley, con trad. adicionales de Joseph R. Allen, Grove Press, Nueva York.

Dai Jiafang, 1987, "Mianlin Tiaozhan de Fansi - Cong Yinyue Xinchao Lun Woguo Xiandai Yinyue de Yihua yu Fan Yihua" ["Profundo replanteamiento de cara al reto: sobre la enajenación y contra enajenación en la música contemporánea china con análisis de la música New Wave], Yinyue Yanjiu [Investigación musical], núm. 1, pp. 44-55.

__ 1991, "Cong Xitonglun Kan Zhongguo Chuantong Yinyue Dansheng Tixi de Changqi Yanxu" ["Estudio de la prolongada permanencia del sistema monofónico de la música china tradicional desde el punto de vista de la teoría sistémica”], Yinyue Yanjiu [Investigación musical], núm. 4, pp. 77-86.

Du Yaxiong, 1995, Zhongguo Minzu Jiben Yueli [Teoría básica de la música nacional china], Zhongguo Wenlian Chuban Gongsi, Beijing.

Feng Wenci, 1998, Zhongwai Yinyue Jiaoliu Shi [Historia de los intercambios musicales entre China y el extranjero], Hunan Jiaoyu Chubanshe, Hunan.

Gao Houyong, 1981, Minzu Qiyue Gailun [Introducción a la música instrumental nacional],Jiangsu Renmin Chubanshe, Suzhou.

Guo Yuhua, 2000, Yishi yu Shehui Bianqian [Cambio ritual y social], Shehui Kexue Wenxian Chubanshe, Beijin.

\footnotetext{
* Los títulos en chino e inglés aparecen entre corchetes en español.
} 
Harrell, Stevan, 1990, "Ethnicity, Local Interests, and the State: Yi Communities in South-West China" ["Etnicidad, intereses locales y el Estado: comunidades Yi en el suroeste de China], Comparative Studies in Society and History, núm. 32, pp. 515-48.

Li Mei, 1998, "Zhongliyin Yuanliu zhi Caixiang" ["Tesis sobre el origen y desarrollo del tono neutral”], Zhongguo Yinyuexue [Musicología china], núm. 3, pp. 116-134.

__ , 2000a, "Zhongliyin” Yinlü Xianxiang de Yanjiu [Investigación sobre el fenómeno del "tono neutral"], tesis doctoral, Departamento de Música, Universidad Normal Fujian, China.

_ xiang de Lüxue Fenxi” ["Análisis de temperamentología del fenómeno del 'tono neutral' en la música popular”], Zhongyang Yinyue Xueyuan Xuebao [Revista del Conservatorio Central de Música], núm. 3, pp. 28-35; núm. 4, pp. $76-83$.

_ 2001, “'Zhongliyin' Laiyi Shengcun de Minjian Yueqi Jizhi” ["Los mecanismos de dependencia de los 'tonos neutrales' en los instrumentos de música popular”], Zhongguo Yinyuexue [Musicología china], núm. 1, pp.1931; núm. 2, pp. 36-52.

Li Yedao, 1990, "Fan Lishi de 'Fansi”" ["Un 'replanteo' que distorsiona la historia”], Yinyue Yanjiu [Investigación musical], núm. 2, pp. 3-10.

Li Yinhai, 1959, Hanzu Diaoshi Jiqi Hesheng [ Modos y armonía de los chinos han], Shanghai Wenyi Chubanshe, Shanghai.

Mao Zedong, 1980 [1942], “Talks at the Yan'an Conference on literature and art" ["Discursos en la Conferencia de Yan'an sobre literatura y arte"], en Mao Zedong, Talks at the Yan'an Conference on Literature and Art: A Translation of the 1943 Text with Commentary, traducido por Bonnie McDougall, Centre for Chinese Studies, University of Michigan, Ann Arbor.

Naribilige, et al., 2001, Renleixue Lilun de Xin Geju [Nueva configuración de las teorías antropológicas], Shehui Kexue Wenxian Chubanshe, Beijing.

Niu Longfei, 1985, Guyue Fayin - Jiayuguan Weijin Mushi Zhuanhua Yueqi Kaozheng Xin Yi Ban [Estudio arqueológico de la música antigua: investigación sobre los instrumentos musicales representados en los ladrillos de la tumba Jiayuguan de las dinastías Wei-Jin], 1a. ed., Gansu Renmin Chubanshe, Lanzhou.

Shen Qia, 1982, "Yinqiang Lun" ["Sobre el yinqiang"], Zhongyang Yinyue Xueyuan Xuebao [Revista del Conservatorio Central de Música], núm. 4, pp. 13-20.

__ 1983, "Yinqiang Lun (xu)" ["Más sobre el yinqiang"], Zhongyang Yinyue Xueyuan Xuebao [Revista del Conservatorio Central de Música], núm. 1, pp.3-11.
Tao Yabin, 1994, Zhongxi Yinyue Jiaoliu Shigao [Historia del intercambio musical entre China y Occidente], Zhongguo Dabaike Quanshu Chubanshe, Beijing.

Tsao Pehyeh y Xue Yibing, 2000, "Research Activities in China: Country Report" ["Actividades de investigación en China: informe del país"], Yearbook for Traditional Music, núm. 32, pp. 150-156.

Thrasher, Alan R., 1993, “China”, en Helen Myers (ed.), Ethnomusicology: Historical and Regional Studies, pp. 311-44, W. W. Norton \& Company, Nueva York y Londres.

Wang Guangqi, 1926, Dongxi Yuezhi zhi Yanjiu [Investigación sobre los sistemas tonales de Oriente y Occidente], Zhonghua Shuju, Shanghai.

—_, 1929a, Dongfang Mingzu zhi Yinyue [Música de los pueblos de Oriente], Zhonghua Shuju, Shanghai.

_-1929b, Yinxue [Acústica], Qizhi Shuju, Shanghai.

_ 1934, Über die Chinesische Klassische Opera (1530-1860 n.Chr.) [Sobre la ópera clásica china (1530-1860)], tesis doctoral, Universidad de Bonn.

Wang Mingming, 1997, Shehui Renleixue yu Zhongguo Yanjiu [Antropología social y estudios chinos], Sanlian Chubanshe, Beijing.

Wang Yi, 1994, Yingyue Zai Shijimo de Zhongguo: Houxiandai Zhuyi yu Dangdai Yinyue [La música en China a finales del siglo: posmodernismo y música contemporánea], Beijing Daxue Chubanshe, Beijing.

Wei Tingge, 1985, "Jianyi Yong Zhongguo Yinyuexue Gainian Daiti Minzu Yinyuexue Gainian” ["Propuesta para sustituir el concepto de etnomusicología por el concepto de musicología china"], Yinyue Yanjiu [Investigación musical], núm. 2, pp. 78 y 37.

Wong, Isabel K. F., 1991, "From Reaction to Synthesis: Chinese Musicology in the Twentieth Century" [ "De la reacción a la síntesis: musicología china en el siglo XX”], en Bruno Nettl y Philip V. Bohlman (eds.), Comparative Musicology and Anthropology of Music, The University of Chicago Press, Chicago, pp. 37-55.

Wu, David Y. H., 1990, "Chinese Minority Policy and the Meaning of Minority Culture: The Example of Bai in Yunnan, China" ["La política de las minorías chinas y el significado de las culturas de minoría: el ejemplo de los bai en Yunnan, China”], Human Organization, vol. 49, núm. 1, pp. 1-13.

Xia Ye, 1982, "Gudai Fandiao Lilun Jiqi Shijian" [“Teoría y praxis de la modulación antiguas"], Yinyue Yishu [El arte de la música ], núm. 3, pp. 18-24.

Xiao Xing, 1989, "Yinyue Lingyu Bixü Jianchi Shehui Zhuyi Wenyi Fangxiang - Zai Jinian 'Jianhua' Fabiao Si Shi Wu Zhounian Zuotanhui Shang de Fayan" ["El enfoque socialista para las artes debe seguirse en el campo de la música: conferencia en el simposio para conmemorar el 45 
aniversario del discurso"], Renmin Yinyue [People's Music], núm. 8, pp. 14-21.

Xiu Jun y Jian Jin, 1993, Zhongguo Yueji Shi [Historia de las prostitutas musicales chinas], Zhongguo Wenlian Chubanshe, Beijing.

Yang Minkang, 1992, Zhongguo Minge yu Xiangtu Shehui [Canciones populares chinas y sociedad local], Jilin Jiaoyu Chubanshe, Changchun.

Yang $\mathrm{Mu}, 1994$, "Academic Ignorance or Political Taboo? Some Issues in China's Study of Its Folk Song Culture" [¿Ignorancia académica o tabú político? Temas en el estudio chino de su cultura de canciones populares], Ethnomusicology, núm. 2, pp. 303-20.

—_, 1997a, "Ye Tan 'Huizu Minjian Yinyue”" ["Sobre la música popular de los pueblos hui"], Zhongyang Yinyue Xueyuan Xuebao [Revista del Conservatorio Central de Música], núm. 1, pp. 47-56.

__ 1997b, "Dangdai Renleixue yu Yinyue Yanjiu Er San Ti" ["Consideraciones sobre la antropología e investigación musical contemporáneas”], Zhongyang Minzu Daxue Xuebao [Revista de la Universidad Central de $\mathrm{Na}$ cionalidades], núm. 6, pp. 25-31, 38. Reimpr. en Zhongguo Renda Shehui Kexue Qingbao Zhongxin: Yinyue Wudao Yanjiu [Centro de Información de Ciencias Sociales de la Universidad Popular China: investigación sobre música y danza], núm. 1, 1998, pp. 10-17.

__ 1998a, "Dangdai Renleixue zhong Youguan Yinyue Yanjiu de Ji Ge Wenti” [“Temas de antropología contemporánea relevantes a la investigación musical"], Zhongyang Yinyue Xueyuan Xuebao [Revista del Conservatorio Central de Música], núm. 1, pp. 6-15.

_ 1998b, "Current State and Methodology of Chinese Music Research in Mainland China" ["Condición actual y metodología de la investigación musical en la China continental"], Tongyang Umak: Journal of the Asian Music Research Institute, Seoul National University, núm. 20, pp. 19-30 (trad. coreana, pp. 31-38).

__ 2000a, "Zaitan Xueshu Guifan yu Wende Wenfeng" ["Más discusión sobre las normas, el estilo y la ética en los trabajos académicos"], Zhongyang Yinyue Xueyuan Xuebao [Revista del Conservatorio Central de Música] núm. 1, pp. 19-30.

_, 200ob, "Zhongguo Yinyue Xingtai Lilun Jianshe yu Hanzu Zhongxinlun Wenti” ["Construcción de la morfología de la música china y temas del han-centrismo”], Yinyue Yanjiu [Investigación musical], núm. 1, pp. 87-93. Reimpr. en Zhongguo Renda Shehui Kexue Qingbao Zhongxin: Yinyue Wudao Yanjiu [Centro de Información de Ciencias Sociales de la Universidad Popular China: Investigación sobre música y danza ], núm. 4, 2000, pp. 4-11. _ $2000 c$, "Mantan Yinyue Renleixue de Dingyi yu Fan- chou" ["Sobre la definición y el alcance de la antropología de la música”], Yinyue Yanjiu [Investigación musical] núm. 3, pp. 81-87. Reimpr. en Zhongguo Renda Shehui Kexue Qingbao Zhongxin: Wutai Yishu [Centro de Información de Ciencias Sociales de la Universidad Popular China: artes escénicas], núm. 1, 2001, pp. 53-59.

__ 2001, "Houxiandai Lilun yu Yinyue Yanjiu" ["Teoría posmoderna e investigación musical"], Zhongyang Yinyue Xueyuan Xuebao [Revista del Conservatorio Central de Música], núm. 1, pp. 3-14; núm. 2, pp. 41-51.

—, 2002 , "Huigu Jiegou Zhuyi” [ "Estructuralismo: un estudio crítico"], Zhongyang Yinyue Xueyuan Xuebao [Revista del Conservatorio Central de Música], núm. 1, pp. 47-55.

Yang Yinliu, 1981, Zhongguo Gudai Yinyue Shigao [Esbozo de la historia de la antigua música china], 2 vols., Renmin Yinyue Chubanseh, Beijing.

Ye Dong, 1982, "Dunhuang Qupu Yanjiu” ["Investigación sobre los manuscritos musicales de Dunhuang"], Yinyue Yishu [El arte de la música], núm. 1, pp. 1-47.

Yu Huiyong, 1997 (1963), “Minzu Minjian Yinyue Qiangci Guanxi Yanjiu” ["Estudio de caso de la relación entre las melodías y los textos de la música étnica y popular"], Yinyue Renwen Shüshi [Narrativas humanistas en música], núm. 1, pp. 54-91.

Yuan Bingchang y Feng Guangyu (eds.), 1998, Zhongguo Shaoshu Minzu Yinyue Shi [Historia de la música de las minorías étnicas chinas], vol. 1, Zhongyang Minzu Daxue Chubanshe, Beijing.

Yuan Jinfang, 1999, Yuezhongxue [Genealogía de la música], Huayue Chubanshe, Beijing.

Zeng Suijin, 1998, Yinyue Shehuixue Gailun [Introducción a la sociología de la música], Wenhua Yishu Chubanshe, Beijing.

Zhao Songguang, 1964, Lun Wudu Xiangsheng Diaoshi Tixi [Acerca del sistema modal del quinto temperamento circular], Shanghai Wenhua Chubanshe, Shanghai.

__, 1993, "Yibi Naoren Yichan de Songkuai Qingli" ["Una solución fácil para una herencia molesta”], Yinyue Yanjiu [Investigación musical], núm. 3, pp. 57-68.

Zhou Xianbao, 1997-98, "Lun Qingyangqiang de Renwen Beijing, Lishi Diwei ji Meixue Jiazhi" ["Sobre el trasfondo cultural, la condición histórica y el valor estético de la melodía de Qingyang"], Yinyue Yanjiu [Investigación musical], núm. 3, 1997, pp. 34-41, 46; núm. 4, 1997, pp. 514; núm. 1, 1998, pp. 13-25, 30.

Zhuang Benli, 1972, "Xun de Lishi yu Bijiao zhi Yanjiu” ["Estudio histórico y comparativo de los xun"], Zhongyang Yanjiuyuan Minzuxue Yanjiusuo Jikan [Revista del Instituto de Investigación en Etnología, Academia Central de Investigación ], núm. 33, Taiwán, pp. 177-229. 